\title{
Mental health consequences of overstretch in the UK armed forces: first phase of a cohort study
}

\author{
Roberto J Rona, professor of public health, ${ }^{1}$ Nicola T Fear, senior lecturer in military epidemiology, ${ }^{2}$ \\ Lisa Hull, study coordinator, ${ }^{1}$ Neil Greenberg, senior lecturer in military psychiatry, ${ }^{2}$ \\ Mark Earnshaw, research fellow, ${ }^{2}$ Matthew Hotopf, professor of general hospital psychiatry, ${ }^{1}$ \\ Simon Wessely, professor of epidemiology and liaison psychiatry ${ }^{1}$
}

'King's College London, King's Centre for Military Health Research, Weston Education Centre, London SE5 9RI

${ }^{2}$ Academic Centre for Defence

Mental Health,

Weston Education Centre

Correspondence to: R J Rona roberto.rona@iop.kcl.ac.uk

doi:10.1136/bmj.39274.585752.BE

\section{ABSTRACT}

Objective To assess the relation between frequency and duration of deployment of UK armed forces personnel on mental health.

Design First phase of a cohort study.

Setting UK armed forces personnel.

Participants Operational history in past three years of a randomly chosen stratified sample of 5547 regulars with experience of deployment.

Main outcome measures Psychological distress (general health questionnaire-12), caseness for post-traumatic stress disorder, physical symptoms, and alcohol use (alcohol use disorders identification test).

Results Personnel who were deployed for 13 months or more in the past three years were more likely to fulfil the criteria for post-traumatic stress disorder (odds ratio $1.55,95 \%$ confidence interval 1.07 to 2.32 ), show caseness on the general health questionnaire $(1.35,1.10$ to 1.63$)$, and have multiple physical symptoms (1.49, 1.19 to 1.87$)$. A significant association was found between duration of deployment and severe alcohol problems. Exposure to combat partly accounted for these associations. The associations between number of deployments in the past three years and mental disorders were less consistent than those related to duration of deployment. Post-traumatic stress disorder was also associated with a mismatch between expectations about the duration of deployment and the reality.

Conclusions A clear and explicit policy on the duration of each deployment of armed forces personnel may reduce the risk of post-traumatic stress disorder. An association was found between deployment for more than a year in the past three years and mental health that might be explained by exposure to combat.

\section{INTRODUCTION}

British commanders have raised concerns about the ability of the armed forces to cope with simultaneous major operations in Iraq and Afghanistan, and the UK armed forces have been asked to do more than was envisaged in the most recent defence review. ${ }^{1-3}$ The National Audit Office reported that the number and frequency of deployments were important reasons for leaving the armed forces. ${ }^{4}$ The UK armed forces acknowledge that excessive deployments may have an effect on job satisfaction and have recommended maximum deployment levels, called the harmony guidelines. Since 2003 the measurement of guideline violations has provided some support to the complaints. ${ }^{4}$ An increase in the pace of deployments has also been recognised in the United States. ${ }^{56}$

The pace of military operations, "operational tempo," may have an effect on health, place strain on the families of military personnel, lower morale, and influence intentions to remain in the armed forces. ${ }^{7-9}$ The nature of the relation between number of deployments and health consequences is far from clear. Overstretch is conceived as over-committing the armed forces at a time of simultaneous major deployments. Thus it should be associated with operational tempo. Deployment is an essential ingredient of military life, is considered a valuable feature of a military career, and for many is the reason for joining up. It can also be a source of conflict and tension within families and may have mental health consequences. ${ }^{78}$

Some of the available reports have considered operational tempo as a characteristic that would have an effect not only on deployments but also on garrison duties and training in general. ${ }^{7-9}$ American researchers have reported an association between number of months of deployment and mental health and physical symptoms, but the associations have been related to the duration of a single deployment. ${ }^{5610}$ No research has been published on the effects of operational tempo in the UK armed forces.

Many features of operational tempo may influence health, including the duration, intensity, location, and type of deployment. ${ }^{6}$ The nature of deployment varies between the three services (naval services (Royal Navy and Royal Marines), Royal Air Force, and army) and there may also be a more subtle effect related to the mismatch between an individual's expectations of deployment and the realities.

We collected information on frequency and duration of deployments in the past three years to assess the possible consequences of the Iraq war on health. ${ }^{11}$ 
We have also obtained information on duration of last deployment and expectation of that deployment's duration. In this paper we assessed the relations between operational tempo and psychological health in the context of the harmony guidelines. ${ }^{4}$ As a secondary outcome we studied the associations between operational tempo and problems at home.

\section{METHODS}

This study is based on the first phase of a cohort study of UK armed forces personnel in which we compared the mental and physical health of those deployed to Iraq between 18 January and 28 April 2003 with those who were in the armed forces but not deployed to Iraq. ${ }^{11} \mathrm{We}$ obtained randomly chosen stratified samples by service and enlistment type (regular or reserve). Operation Telic is the codename for the current operations in Iraq. Full details of the study and responders can be found elsewhere. ${ }^{11}$ In total 4722 personnel who were deployed on Telic 1 (the war fighting phase) and 5550 personnel who were not deployed on Telic 1 completed a questionnaire on experiences of the military, deployment, and post-deployment and on health outcomes. The overall response rate was $60 \%$ for regulars, deployed or not, and $62 \%$ for those deployed on Telic 1 . We approached those in the sample at least three times to elicit completion of the questionnaire, unless they refused. We excluded those with no deployment experience in the past three years because our objective was to assess the effect of duration and frequency of deployment and not the contrast between deployed and non-deployed personnel, which has already been reported. ${ }^{11}$ We also excluded 953 reserves with deployment experience because their deployments in the past three years were noticeably shorter and less frequent than those in the regular services. The study sample was 5547 regulars. Most of the participants (98.5\%) completed the questionnaire after deployment.

\section{Outcome measures}

We measured psychological distress, using the 12 item general health questionnaire ${ }^{1213}$; post-traumatic stress disorder, using the 17 item national centre for posttraumatic stress disorder checklist ${ }^{14}$; fatigue, using the
Chalder fatigue scale ${ }^{15}$; physical symptoms, using a checklist of 53 symptoms similar to that used in our previous study of Gulf War veterans ${ }^{16}$; and use of alcohol, using the alcohol use disorders identification test developed by the World Health Organization. ${ }^{17}$ The defined cut-off values for each of the measures were a score of four or more for the general health questionnaire and fatigue scale, a score of 50 or more for the post-traumatic stress disorder checklist, a score of 18 or more for physical symptoms, and a score of 16 or more for the alcohol use disorders identification test, which according to the WHO corresponds to severe alcohol problems. ${ }^{17}$ Other outcomes were intentions to stay in the armed forces and problems at home either during or after deployment, including not receiving enough support from the family, partner finishing the relationship, problems with children, serious financial problems, and other major problems at home.

\section{Main independent factors}

To evaluate operational tempo we asked participants roughly how many months in the past three years they had been away on deployment. We assessed number of deployments by whether the participants answered yes to any deployments to Afghanistan, Bosnia, Kosovo, Macedonia, northern or southern Iraq and Kuwait, and Sierra Leone. As the main question was whether duration of deployments greater than those set out in the harmony guidelines have an effect on psychological health we created a category in which participants could state whether they were deployed above the guidelines. Based on the army guideline for a unit, of six months' operational tour with 24 months' interval during 36 months, a unit could not be deployed for more than 12 months. We subdivided the remaining deployment periods into three categories of equal duration. Some service personnel in the group 8 to 12 months could have been deployed over the recommended limit. In a separate analysis we assessed the difference between actual and expected duration in theatre on the last deployment according to three categories: actual was same as expected, actual was less than expected, and actual was more than expected.

Table 1 Duration and frequency of deployments since 2000 for about a three year period, by service and combat role (regulars only). Values are numbers (percentages)

\begin{tabular}{|c|c|c|c|c|c|c|}
\hline Variable & Total $(n=5547)$ & $\begin{array}{l}\text { Royal Navy } \\
(n=568)\end{array}$ & $\begin{array}{l}\text { Royal Marines } \\
\qquad(n=261)\end{array}$ & Army $(n=3684)$ & $\begin{array}{l}\text { Royal Air Force } \\
\quad(n=1034)\end{array}$ & Combat $(n=1521)$ \\
\hline \multicolumn{7}{|c|}{$\begin{array}{l}\text { Duration of deployment } \\
\text { (months): }\end{array}$} \\
\hline$<5$ & $896(16.2)$ & $52(9.2)$ & $32(12.3)$ & $520(14.1)$ & $292(28.2)$ & $130(8.6)$ \\
\hline $5-8$ & $1811(32.7)$ & $121(21.3)$ & $54(20.7)$ & $1221(33.1)$ & $415(40.1)$ & $414(27.2)$ \\
\hline $9-12$ & $1630(29.4)$ & $162(28.5)$ & $83(31.8)$ & $1163(31.6)$ & $222(21.5)$ & $512(33.7)$ \\
\hline$\geq 13$ & $1210(21.8)$ & $233(41.0)$ & $92(35.3)$ & $780(21.2)$ & $105(10.2)$ & $465(30.6)$ \\
\hline \multicolumn{7}{|c|}{ No of deployments: } \\
\hline 1 & $3336(60.1)$ & $386(68.0)$ & $136(52.1)$ & $2175(59.0)$ & $639(61.8)$ & $886(58.3)$ \\
\hline 2 & $1691(30.5)$ & $146(25.7)$ & $86(33.0)$ & $1207(32.8)$ & $252(24.4)$ & $520(34.2)$ \\
\hline$\geq 3$ & $520(9.4)$ & $36(6.3)$ & 39 (14.9) & $302(8.2)$ & $143(13.8)$ & $115(7.6)$ \\
\hline
\end{tabular}




\section{Confounders and explanatory variables}

All analyses were adjusted for the possible confounders of age, sex, serving status (whether participant remained in the services), marital status, and service. We further adjusted for role in theatre (combat, combat support, combat service support), type of deployment (war in at least one deployment, peace enforcement operations), time spent in a forward area in close contact with the enemy (not at all, up to a week, up to a month, more than a month), and problems at home during and after deployment, collected for the last deployment.

\section{Analysis}

We carried out multiple logistic regressions for the sample regardless of service but adjusted for service. We also carried out analyses separately for each service, as the experience of deployment may vary between them. Two models were used to analyse each of the outcomes. In the first we adjusted for variables that were considered confounders and in the second we further adjusted for possible explanatory variables. We analysed separately for duration and number of deployments and the difference between expected and actual duration for the last deployment. In the analyses we assessed the odds ratios and 95\% confidence intervals for each group compared with the reference group (one deployment, 5-8 months on deployment in past three years, or no difference between actual and expected duration of deployment). We also assessed other effects associated with experience of deployment. For all analyses we used Stata version 9.2.

\section{RESULTS}

Overall 5547 (63.9\%) of 8686 regulars who completed the questionnaire had participated in at least one deployment in the past three years. Royal Air Force personnel had less prolonged periods of deployments than personnel in the other services, whereas the Royal Navy and Royal Marines had proportionally more personnel with long periods of deployment (table 1). Most of those deployed had one or two deployments in the past three years. Almost a third of those with a combat role in their last deployment had been deployed for 13 months or more in the past three years.

A consistent association was found between prolonged deployments ( $\geq 13$ months) and problems at home both during and after deployment (table 2). Although consistent the effect size was small and was reduced after adjustment for role in theatre, time spent in a forward area, and type of deployment (table 2). No association was found between number of deployments and problems at home, or between number and duration of deployments and intention to stay in the armed forces (data not shown).

The prevalence of all psychological symptoms was higher among those deployed for 13 months or more (table 3). This was shown by a consistent association between the time spent on deployment (category $\geq$ 13 months) and psychological symptoms when adjusted for the confounding factors in the first

Table 2 | Association between duration and number of deployments since 2000 , for about a three year period, and problems at home during and after deployment $(n=5547)$

\begin{tabular}{|c|c|c|c|}
\hline Variables & No (\%) & Adjusted odds ratio $(95 \% \mathrm{Cl})^{\star}$ & Odds ratio $(95 \% \mathrm{Cl}) \dagger$ \\
\hline \multicolumn{4}{|c|}{ Problems at home during last deployment } \\
\hline \multicolumn{4}{|c|}{$\begin{array}{l}\text { Duration of deployments } \\
\text { (months): }\end{array}$} \\
\hline$<5$ & $163(18.2)$ & 1.04 (0.84 to 1.29$)$ & 1.14 (0.92 to 1.42$)$ \\
\hline $5-8$ & $329(18.2)$ & 1.00 & 1.00 \\
\hline $9-12$ & $325(20.0)$ & $1.10(0.93$ to 1.31$)$ & $1.12(0.93$ to 1.34$)$ \\
\hline$\geq 13$ & $267(22.1)$ & $1.28(1.06$ to 1.54$)$ & $1.22(1.00$ to 1.48$)$ \\
\hline \multicolumn{4}{|c|}{ No of deployments: } \\
\hline 1 & $638(19.1)$ & 1.00 & 1.00 \\
\hline 2 & $338(20.0)$ & 1.04 (0.89 to 1.20$)$ & $1.02(0.87$ to 1.19$)$ \\
\hline$\geq 3$ & $108(20.8)$ & $1.15(0.91$ to 1.45$)$ & 1.11 (0.87 to 1.41$)$ \\
\hline \multicolumn{4}{|c|}{ Problems at home after last deployment } \\
\hline \multicolumn{4}{|c|}{$\begin{array}{l}\text { Duration of deployments } \\
\text { (months): }\end{array}$} \\
\hline$<5$ & $144(18.2)$ & 1.04 (0.83 to 1.30$)$ & 1.11 (0.89 to 1.40$)$ \\
\hline $5-8$ & $298(18.0)$ & 1.00 & 1.00 \\
\hline $9-12$ & $291(19.3)$ & 1.03 (0.86 to 1.24$)$ & 0.97 (0.80 to 1.17$)$ \\
\hline$\geq 13$ & $248(22.5)$ & 1.25 (1.02 to 1.52$)$ & $1.14(0.93$ to 1.40$)$ \\
\hline \multicolumn{4}{|c|}{ No of deployments: } \\
\hline 1 & $561(18.8)$ & 1.00 & 1.00 \\
\hline 2 & $325(20.6)$ & 1.14 (0.97 to 1.33$)$ & 1.09 (0.92 to 1.28$)$ \\
\hline$\geq 3$ & $95(19.4)$ & 1.14 (0.89 to 1.45$)$ & 1.13 (0.87 to 1.45$)$ \\
\hline
\end{tabular}

Information on problems at home was missing for two regulars during deployment and 492 regulars after deployment.

${ }^{\star}$ Adjusted for sex, age, serving status, rank, service, and marital status.

†Adjusted for sex, age, serving status, rank, service, marital status, role in theatre, time spent in a forward area, and type of deployment. 
model. The prevalence of severe alcohol problems increased with duration of deployment ( $\mathrm{P}$ for trend $<0.001)$. Role in theatre, time spent in a forward area, type of deployment, and problems at home partly explained the associations in relation to the posttraumatic stress disorder checklist, psychological distress, and, to a lesser extent, multiple physical symptoms. No single variable explained the decrease of association between deployment for more than 13 months or more and psychological symptoms. This association was also observed for fatigue caseness but became non-significant after adjustment for problems at home, time spent in a forward area, type of deployment, and role in theatre (data not shown).

The relation between number of deployments and prevalence of psychological symptoms was less clear (table 3). An association was found between those with three or more deployments and caseness $(\mathrm{P}=0.05)$, but this became non-significant after adjustment for explanatory factors (table 3). Some evidence was found for an association between number of deployments and caseness on the post-traumatic stress disorder checklist and multiple physical symptoms, but the associations were non-significant $(\mathrm{P}>0.05)$.

Effect modifications were not found for deployment and type of service on each of the psychological outcomes. The results for the Royal Navy and for the army plus the Royal Marines were generally consistent with the results for all three services combined, but this was not the case for the Royal Air Force (data not shown). In the Royal Air Force, the group with three or more deployments was associated with caseness on the posttraumatic stress disorder checklist and psychological distress (associations were of borderline statistical significance). The association decreased after adjustment for the explanatory variables.

Table 4 shows the relation between the difference in actual and expected duration of deployment for the most recent deployment and psychological symptoms. A moderately strong association was found between a longer than expected period of deployment and caseness on the post-traumatic stress disorder checklist, which was not found for the other psychological outcomes. The association between longer than expected period of deployment and caseness on the posttraumatic stress disorder checklist persisted in analyses carried out separately for the Royal Navy (odds ratio $12.34,95 \%$ confidence interval 1.02 to 148.73 ) and the army plus the Royal Marines (2.18, 1.09 to 4.36$)$.

\section{DISCUSSION}

Deployment for 13 months or more over a three year period was consistently associated with problems at home during and after deployment and with psychological symptoms. The effect sizes were small for problems at home and moderate for psychological symptoms. A combat role during deployment, type of deployment, spending time in a forward area in close contact with the enemy, and problems at home partly explained these associations. The associations were less consistent for number of deployments. A noticeable association was found between an expectation that the most recent deployment would be shorter than it actually was and caseness for post-traumatic stress disorder. This association was also observed separately in the Royal Navy and the army plus Royal Marines and the effect sizes were moderately large.

\section{Data quality}

Although information bias in cross sectional studies cannot be excluded this is unlikely in our study because the main independent variables were objective and the participants were not specifically informed about the use of the data to assess the effect of "operational tempo," the pace of military operations. Omission of information or forgetfulness could have

\begin{tabular}{|c|c|c|c|c|c|c|c|c|c|c|c|c|}
\hline \multirow[b]{2}{*}{ Variables } & \multicolumn{3}{|c|}{ Post-traumatic stress disorder } & \multicolumn{3}{|c|}{ Psychological distress case } & \multicolumn{3}{|c|}{ Multiple physical symptoms } & \multicolumn{3}{|c|}{ Severe alcohol problems } \\
\hline & No (\%) & $\begin{array}{l}\text { Odds ratio } \\
(95 \% \mathrm{Cl})^{\star}\end{array}$ & $\begin{array}{l}\text { Odds ratio } \\
(95 \% \mathrm{Cl}) \dagger\end{array}$ & No (\%) & $\begin{array}{l}\text { Odds ratio } \\
(95 \% \mathrm{Cl})^{\star}\end{array}$ & $\begin{array}{l}\text { Odds ratio } \\
(95 \% \mathrm{Cl}) \dagger\end{array}$ & No (\%) & $\begin{array}{l}\text { Odds ratio } \\
(95 \% \mathrm{Cl})^{\star}\end{array}$ & $\begin{array}{l}\text { Odds ratio } \\
(95 \% \mathrm{Cl}) \dagger\end{array}$ & No (\%) & $\begin{array}{l}\text { Odds ratio } \\
(95 \% \mathrm{Cl})^{\star}\end{array}$ & $\begin{array}{l}\text { Odds ratio } \\
(95 \% \mathrm{Cl}) \dagger\end{array}$ \\
\hline \multicolumn{13}{|c|}{$\begin{array}{l}\text { Duration of deployment } \\
\text { (months): }\end{array}$} \\
\hline$<5$ & $26(3.0)$ & $\begin{array}{l}1.00(0.61 \\
\text { to } 1.64)\end{array}$ & $\begin{array}{l}1.13(0.67 \\
\text { to } 1.92)\end{array}$ & 169 (19.1) & $\begin{array}{l}1.12(0.90 \\
\text { to } 1.38)\end{array}$ & $\begin{array}{l}1.15(0.91 \\
\text { to } 1.45)\end{array}$ & $88(9.8)$ & $\begin{array}{l}0.93(0.71 \\
\text { to } 1.22)\end{array}$ & $\begin{array}{l}0.97(0.72 \\
\text { to } 1.31)\end{array}$ & $96(10.9)$ & $\begin{array}{l}0.70(0.54 \\
\text { to } 0.91)\end{array}$ & $\begin{array}{c}0.66(0.50 \text { to } \\
0.88)\end{array}$ \\
\hline $5-8$ & $55(3.1)$ & 1.00 & 1.00 & $308(17.3)$ & 1.00 & 1.00 & $192(10.6)$ & 1.00 & 1.00 & $298(16.7)$ & 1.00 & 1.00 \\
\hline $9-12$ & $60(3.8)$ & $\begin{array}{l}1.10(0.75 \\
\text { to } 1.61)\end{array}$ & $\begin{array}{l}0.96(0.63 \\
\text { to } 1.45)\end{array}$ & $308(19.2)$ & $\begin{array}{l}1.10(0.92 \\
\text { to } 1.31)\end{array}$ & $\begin{array}{l}1.00(0.82 \\
\text { to } 1.22)\end{array}$ & $173(10.6)$ & $\begin{array}{l}0.97(0.78 \\
\text { to } 1.21)\end{array}$ & $\begin{array}{l}0.88(0.69 \\
\text { to } 1.12)\end{array}$ & $305(19.0)$ & $\begin{array}{l}1.02(0.85 \\
\text { to } 1.23)\end{array}$ & $\begin{array}{c}0.99(0.82 \text { to } \\
1.21)\end{array}$ \\
\hline$\geq 13$ & $62(5.2)$ & $\begin{array}{l}1.58(1.07 \\
\text { to } 2.32)\end{array}$ & $\begin{array}{l}1.24(0.81 \\
\text { to } 1.89)\end{array}$ & $257(21.8)$ & $\begin{array}{l}1.35(1.10 \\
\text { to } 1.63)\end{array}$ & $\begin{array}{l}1.17(0.94 \\
\text { to } 1.44)\end{array}$ & $175(14.5)$ & $\begin{array}{l}1.49(1.19 \\
\text { to } 1.87)\end{array}$ & $\begin{array}{l}1.28(0.99 \\
\text { to } 1.64)\end{array}$ & $285(23.9)$ & $\begin{array}{l}1.35(1.11 \\
\text { to } 1.64)\end{array}$ & $\begin{array}{c}1.18 \text { (0.95 to } \\
1.46)\end{array}$ \\
\hline \multicolumn{13}{|c|}{ No of deployments: } \\
\hline 1 & $121(3.8)$ & 1.00 & 1.00 & $616(18.8)$ & 1.00 & 1.00 & $345(10.3)$ & 1.00 & 1.00 & $592(18.1)$ & 1.00 & 1.00 \\
\hline 2 & $57(3.4)$ & $\begin{array}{l}0.93(0.67 \\
\text { to } 1.30)\end{array}$ & $\begin{array}{l}0.85(0.59 \\
\text { to } 1.22)\end{array}$ & $320(19.2)$ & $\begin{array}{l}1.05(0.90 \\
\text { to } 1.23)\end{array}$ & $\begin{array}{l}1.02(0.86 \\
\text { to } 1.21)\end{array}$ & $219(13.0)$ & $\begin{array}{l}1.25(1.04 \\
\text { to } 1.51)\end{array}$ & $\begin{array}{l}1.17(0.96 \\
\text { to } 1.44)\end{array}$ & $301(18.0)$ & $\begin{array}{l}1.10(0.93 \\
\text { to } 1.29)\end{array}$ & $\begin{array}{c}1.10 \text { (0.92 to } \\
1.31)\end{array}$ \\
\hline$\geq 3$ & $25(4.9)$ & $\begin{array}{c}1.49(0.94 \\
\text { to } 2.37)\end{array}$ & $\begin{array}{l}1.32(0.79 \\
\text { to } 2.19)\end{array}$ & $106(21.0)$ & $\begin{array}{l}1.27(1.00 \\
\text { to } 1.61)\end{array}$ & $\begin{array}{l}1.15(0.89 \\
\text { to } 1.50)\end{array}$ & $64(12.3)$ & $\begin{array}{l}1.29(0.97 \\
\text { to } 1.73)\end{array}$ & $\begin{array}{l}1.20(0.88 \\
\text { to } 1.65)\end{array}$ & $91(17.7)$ & $\begin{array}{l}1.23(0.95 \\
\text { to } 1.59)\end{array}$ & $\begin{array}{c}1.28 \text { (0.97 to } \\
1.68)\end{array}$ \\
\hline
\end{tabular}


affected responses but this should not have been a major problem in a three year period. Only $6 \%$ of people allocated to the Telic 1 group by the Defence Analytical Services Agency did not endorse this deployment in the questionnaire. The main reason for the disagreement was confusion about the end date of Telic 1. Reverse causality is an unlikely explanation for the association between duration of deployment and psychological symptoms. It is difficult to imagine that service personnel with psychological symptoms would serve in a deployment when their unit did not or that commanding officers would choose to deploy those with psychological symptoms more often than others. If anything the opposite would be more likely. We cannot exclude reverse causality in the analysis assessing the difference between expected and actual duration of deployment and post-traumatic stress disorder - that is, participants with post-traumatic stress disorder may have been hoping to have shorter periods of deployment than other participants. We believe that the specificity and consistency of the finding in contrast with other psychological symptoms studied supports the view that this may be causal. In a survey of US troops in Iraq, uncertain date of returning home was a major source of concern and increased psychological distress. ${ }^{18}$ One study commented that there was high level of psychological distress in personnel when date of exit from theatre was uncertain or when doubted because of changes of dates in the past. $^{19}$

We do not have data on psychological symptoms before deployment, as is available for a smaller cohort study. ${ }^{20}$ Such information would have been helpful to ensure that reverse causality could not have explained the association between expected and actual duration of deployment and post-traumatic stress disorder. We have already shown, however, that the presence of psychological symptoms before deployment has a minimal effect on long term mental health in military personnel. ${ }^{20}$ The assessment of psychological symptoms before deployment would have been less helpful in the analysis of duration of deployment over the past three years because there was great variation in the number of operations in which service personnel participated. Some people would have needed multiple psychological assessments and others only one and, on the basis of our previous study, the consistency between assessments would have been low and difficult to include in the current analysis. ${ }^{20}$

The army started monitoring deployment in the latter part of 2003; instructions for the army in the harmony guidelines were released in May 2005. Seventy six per cent of the regulars completed the questionnaire before the document was released and $90 \%$ completed it by the end of October 2005, when few would have known about the document.

In the harmony guidelines the definition of excessive deployment in the army does not correspond to that for the naval services or the Royal Air Force. The only reasonable analytical approach was to use one definition for participants regardless of service. As we did not have independent information on the intensity of combat such information was provided by participants. In this study we were not able to identify a precise traumatic exposure as being responsible for the symptoms of post-traumatic stress disorder.

Table 4 | Association between difference of expected and actual duration of last deployment and psychological symptoms

\begin{tabular}{|c|c|c|c|}
\hline Variables & No (\%) & Odds ratio $(95 \% \mathrm{Cl})^{*}$ & Odds ratio $(95 \% \mathrm{Cl}) \dagger$ \\
\hline \multicolumn{4}{|c|}{ Caseness on post-traumatic stress disorder checklist } \\
\hline \multicolumn{4}{|l|}{ Duration of deployment: } \\
\hline Same as expected & $29(2.7)$ & 1.00 & 1.00 \\
\hline Less than expected & $48(3.1)$ & $1.04(0.64$ to 1.76$)$ & 1.10 (0.66 to 1.84$)$ \\
\hline More than expected & $17(6.4)$ & 2.27 (1.21 to 4.24$)$ & 2.38 (1.21 to 4.65$)$ \\
\hline \multicolumn{4}{|c|}{ Caseness on general health questionnaire } \\
\hline \multicolumn{4}{|l|}{ Duration of deployment: } \\
\hline Same as expected & $177(16.5)$ & 1.00 & 1.00 \\
\hline Less than expected & $269(17.4)$ & $1.06(0.86$ to 1.31$)$ & 1.13 (0.89 to 1.42$)$ \\
\hline More than expected & $57(21.4)$ & 1.34 (0.95 to 1.88$)$ & $1.30(0.90$ to 1.89$)$ \\
\hline \multicolumn{4}{|c|}{ Multiple physical symptoms } \\
\hline \multicolumn{4}{|l|}{ Duration of deployment: } \\
\hline Same as expected & $103(9.5)$ & 1.00 & 1.00 \\
\hline Less than expected & $183(11.8)$ & 1.25 (0.96 to 1.62$)$ & 1.27 (0.96 to 1.68$)$ \\
\hline More than expected & $22(8.1)$ & $0.82(0.51$ to 1.34$)$ & 0.82 (0.49 to 1.36$)$ \\
\hline \multicolumn{4}{|l|}{ Severe alcohol problem } \\
\hline \multicolumn{4}{|l|}{ Duration of deployment: } \\
\hline Same as expected & $177(16.5)$ & 1.00 & 1.00 \\
\hline Less than expected & $266(17.2)$ & $1.03(0.87$ to 1.28$)$ & 1.02 (0.81 to 1.29$)$ \\
\hline More than expected & $52(19.3)$ & 1.11 (0.77 to 1.59$)$ & 1.11 (0.76 to 1.62$)$ \\
\hline
\end{tabular}

*Adjusted for sex, age, serving status, rank, service, and marital status.

†Adjusted for sex, age, serving status, rank, service, marital status, role in theatre, time spent in a forward area, and problems at home. 


\section{WHAT IS ALREADY KNOWN ON THIS TOPIC}

UK armed forces are being deployed more often than previously, so called overstretch

To allow objective monitoring the UK armed forces have recommended maximum

deployment levels, called harmony guidelines

\section{WHAT THIS STUDY ADDS}

Duration of deployment above established guidelines is associated with more mental health problems

Combat exposure, type of deployment, and problems at home partly account for these associations

An association was found between expectation that duration of most recent deployment would be shorter than it actually was and post-traumatic stress disorder

\section{Duration of deployments and mental health}

Several reports have assessed duration of deployment in relation to health although most have been restricted to one specific deployment. ${ }^{56101921-24}$ Most of these studies have shown that psychological distress is associated with duration of deployment. ${ }^{561021-24}$ The comparison of duration of deployment has not been standardised and, with exceptions, ${ }^{5}$ adjustment for possible confounders has not been carried out.

No previous analysis has looked at duration of deployment over a long period, such as the three years in the current study. This construct is important because it is nearer to the concept of "overstretch" in a period of multiple deployments. Overstretch conveys the notion that smaller forces are carrying out an increasing number of operational duties worldwide. ${ }^{25}$ The harmony guidelines provide a tangible measure of overstretch. Our analyses provide evidence that deployment above this limit has some generalised adverse psychological consequences. With the exception of severe alcohol problems a threshold of deployment duration exists beyond which a deterioration in psychological health can be shown. It is possible that the current policy of the US army for one year deployments may in part explain the differences in prevalence of post-traumatic stress disorder between the two forces, even taking into account the higher combat intensity experienced by US forces compared with UK forces in Iraq. ${ }^{1126}$

Type of deployment, time spent in a forward area, and problems at home both during and after deployment reduce the level of the associations between duration of deployment and psychological outcomes. In relation to problems at home after deployment, our results suggest that many problems bottled-up during a long period of deployment may come to light on returning home.

We also found that alcohol intake has increased in the UK armed forces and that the increase has been more than in the civilian population. ${ }^{27}$ Our study indicates that duration of deployment may be a factor in the high alcohol intake of military personnel. In contrast with other outcomes of psychological health, in which the association was mainly shown in those deployed for more than 12 months in the past
36 months, the risk of alcohol misuse increased with increasing duration of deployment.

\section{Number of deployments and mental health}

The association between number of deployments and psychological symptoms was less consistent than for duration of deployment. One study proposed that successive deployments could have a stress buffering effect; thus an initial deployment could decrease the likelihood of psychological symptoms in subsequent deployments. ${ }^{5}$ We did not find evidence in support of such a hypothesis. Another study found no association between number of deployments in the past three years and the brief symptoms inventory. ${ }^{19}$ In our study many of those with several deployments were deployed for short periods. Although this pattern was a characteristic of the Royal Air Force our results were similar in each of the services. A possible explanation for our results is that shorter periods of deployment with intervals of rest and recuperation may act as a buffer against the development of psychological symptoms.

\section{Conclusions}

Our results indicate that adherence to a clear and explicit policy on duration of each deployment may have beneficial effects on mental health. Overstretch in the UK armed forces may have consequences on problems at home, and deterioration of psychological health may be more apparent in those directly exposed to combat.

We thank the UK Ministry of Defence for their cooperation; in particular we thank the Defence Medical Services Department, the Defence Analytical Services Agency, the Armed Forces Personnel Administration Agency, and the Veteran's Policy Unit.

Contributors: RJR planned and sought funding for the study, supervised data collection, designed analysis, and was the lead author in writing the paper. NTF was involved with the data collection, was responsible for the data processing, discussed and carried out the analysis, and wrote this paper. LH was responsible for the coordination of this study and was involved in the planning of the study and writing of the paper. ME was involved in the planning and writing of the paper. NG was involved in the planning and writing of the paper. $\mathrm{MH}$ sought funding and participated in the planning, supervision of data collection, and writing of the paper. SW sought funding for, and led the planning of, the study, supervised data collection, and made comments on the analysis and writing of the paper. All authors approved the final version. RJR and NTF are guarantors for the paper.

Funding: The study was funded by the UK Ministry of Defence. The work was independent of the funders but a copy of the paper was sent to them. The Defence Analytical Services Agency provided the sampling frames of the armed forces. We indicated our requirements to obtain random samples for the study and discussed feasibility and operational issues with the Defence Analytical Services Agency. The agency supplied addresses and identifiers directly related to personnel in the random samples and deployment allocation in relation to the Iraq war (Telic 1). The funders did not participate in data collection, data processing, data analysis, or interpretation of findings.

Competing interests: SW is honorary civilian consultant adviser to the British army. NG and ME are members of the Defence Medical Services seconded to King's College London. Although NG and ME are paid from Ministr of Defence funds they have not been directed in any way by the ministry in relation to this publication.

Ethical approval: This study was approved by the Ministry of Defence (Navy) personnel research ethics committee and the King's College Hospital local research ethics committee. 
1 BBC News. UK Army "not too small to cope." The Ministry of Defence has denied the army is too small to cope with its current overseas commitments. 22 Dec 2006. http://news.bbc.co.uk/1/hi/ uk_politics/6202331.stm.

2 Jones G. More troops for Afghanistan. Last updated 24 Jan 2007. www.telegraph.co.uk/news/main.jhtml?xml=/news/2007/01/23/ wafghan23.xml.

3 Summers $D$ and agencies. Blair pledges increased military spending as he defends intervention. 12 Jan 2007.www.guardian.co.uk/ military/story/0,1988945,00.html.

4 National Audit Office. Ministry of Defence. Recruitment and retention in the armed forces. Report by the Controller and Auditor General; HC 1633-I session 2005-6; 3 Nov 2006.

5 Adler AB, Huffman AH, Bliese PD, Castro CA. The impact of deployment length and experience on the well-being of male and female soldiers. J Occup Health Psychol 2005;10:121-37.

6 Castro CA, Adler AB. OPTEMPO: effect on soldier and unit readiness. Parameters 1999:86-95. Carlisle-www.army.mil/usawc/ Parameters/99automn/castro.htm.

7 Adams GA, Durand DB, Burrell L, Teitelbaum JM, Pehrson KL, Hawkins JP. Direct and indirect effects of operations tempo on outcomes for soldier and spouses. Military Psychol 2005;17:229-46.

8 Britt TW, Dawson CR. Predicting work-family conflict from workload, job attitudes, group attributes, and health: a longitudinal study. Military Psychol 2005;17:203-27.

9 Dolan CA, Adler AB, Thomas JL, Castro CA. Operations tempo and soldier health: the moderating effect of wellness behavior. Military Psychol 2005;17:157-74.

10 The Canadian Community Health Survey (CCHS)-Cycle 1.2. Complementary information for the release of the Canadian Forces supplement (September 2003). www.statcan.ca/english/concepts/ health/cycle1_2/supp.htm.

11 Hotopf M, Hull L, Fear NT, Browne T, Horn O, Iversen A, et al. The health of UK military personnel who deployed to the 2003 Iraq war: a cohort study. Lancet 2006;367:1731-41.

12 Goldberg D, Williams P. A users' guide to the general health questionnaire. Windsor: NFER-Nelson, 1988.

13 Goldberg DP, Gater R, Sartorius N, Ustun TB, Piccinelli M, Gureje O, et al. The validity of two versions of the GHQ in the WHO study of mental illness in general health care. Psychol Med 1997;27:191-7.

14 Blanchard EB, Jones-Alexander J, Buckely TC, Forneris CA. Psychometric properties of the PTSD checklist (PCL). Behav Res Ther 1996;34:669-73.

15 Chalder T, Berelowitz G, Pawlikowska T, Watts L. Development of a fatigue scale. J Psychosom Res 1993;37:147-53.
16 Unwin C, Blatchley N, Coker W, Ferry S, Hotopf M, Hull L, et al. Health of UK servicemen who served in Persian Gulf war. Lancet 1999;353:169-78.

17 Babor TF, Higgins-Biddle JC, Saunders JB, Monteiro MG. AUDIT: the alcohol use disorders identification test. 2nd ed. Geneva: World Health Organization, 2001.

18 Operation Iraqi Freedom (OIF). Mental health advisory team (MHAT) report, 16 Dec 2003. Office of the US. Army Surgeon General and HQ DA G-1. Office of the US Army Surgeon General. www.pbs.org/wgbh/ pages/frontline/shows/heart/readings/mhat.pdf (accessed 18 Jul 2007).

19 Ritzer DR, Campbell SJ, Valentine JN. Human dimensions research during operation "joint guard," Bosnia. Army Med Dep / 1999;1/2/ 3:5-16.

20 Rona RJ, Hooper R, Jones M, Hull L, Browne T, Horn O, et al. Would mental health screening of the UK armed forces before the Iraq war have prevented subsequent psychological morbidity? A follow up study. BMJ 2006;333:991-4.

21 Balloni E, Valentino M, Occhiolini L, DiMascio C, Cannone D, Schioppa FS. Factors influencing psychological stress levels of Italian peacekeepers in Bosnia. Military Med 2000;165:911-5.

22 Da Silva T, Paiva T, Elsa T, Rodriguez A, Ricardo A. Portuguese military in peacekeeping missions. A psychological evaluation model: epistemological and methodological contribution. In: Proceedings of the 34th International Applied Military Psychology Symposium. Paris: Centre d'Etudes en Science Sociales de la Defense, 1998:72084.

23 Pierce PF. Physical and emotional health of Gulf war veteran women. Aviat Space Environ Med 1997;68:317-21.

24 Vincent C, Chamberlain K, Long N. Relation of military service variables to posttraumatic stress disorder in New Zealand Vietnam war veterans. Military Med 1994;159:322-6.

25 Dandeker C, French C, Birtles C, Wessely S. Deployment experiences of British army wives before, during and after deployment: satisfaction with military life and use of support networks. 2006 HFM Symposium on "Human dimensions in military operations," Brussels, April 2006.

26 Hoge C, Castro CA, Messer SC, McGurk D, Cotting DI, Koffman RL. Combat duty in Iraq and Afghanistan mental health problems, barriers to care. New Engl J Med 2004;351:13-22.

27 Fear NT, Iversen A, Meltzer H, Workman L, Hull L, Greenberg N, et al. Patterns of drinking in the UK armed forces. Addiction (in press).

Accepted: 28 June 2007 